\title{
Network Process Model for Group Choice of a Multinational Enterprises’ Entry Mode
}

\author{
Su-Chuan Shih \\ Providence University \\ E-Mail: scshih@pu.edu.tw
}

\begin{abstract}
Entry mode selection is an important and practical task for an enterprise when entering a foreign market. No method in the literature applies directly. The aim of this paper is to discuss and develop an entry mode selection model. Based on an Analytic Network Process (ANP) framework, the model is for a photoelectric lens company in Taiwan looking to invest in the Vietnamese or Thai markets. The ANP is a general theory of relative measurement used to composite-priority-ration scales from individual-ration scales that represent the differential influence of factors that interact to control determinants. Based upon the theories of Transaction Cost Economics and Institutional Approach, four determinants are significant: general transaction costs, asset specificity, internal environmental institutions, and host-country environmental institutions and the 12 indicators embedded in them. Because some portions of the data are inaccessible, hypothetical numbers supplement the actual data to illustrate the processes. The paper also illustrates how a group of judges comprised of company stakeholders can implement the ANP model for selecting entry modes.
\end{abstract}

Keywords: entry mode selection, Analytical Network Process (ANP), Analytical Hieratical Process (AHP)

\section{INTRODUCTION}

In today's global marketplace, many firms believe it is necessary to engage in one or more entry modes, such as export, licensing, strategic alliance, joint venture, or wholly owned subsidiaries. The choice of entry mode in a foreign market can have significant and far-reaching consequences on a firm's performance and survival (Makino \& Beamish, 1998). The entry mode chosen affects the amount of control the firm retains over its business activities and the degree to which it succeeds in foreign markets (Erramilli \& Rao, 1993). Inappropriate entry mode decisions are difficult to 
change when long-term contracts and large resource commitments are made. For example, an inappropriate entry mode may block opportunities and substantially limit the range of strategic options open to the firm (Taylor, Zou \& Osland, 1998); it may result in substantial losses to the firm, including exit from the foreign market.

Prior explanations for choice of entry mode draw extensively from the transactions cost approach (Erramilli \& Rao, 1993; Anderson \& Gatignon, 1986). Explanations based on transaction cost emphasize the role of control. Despite intensive research, there is still a lack of consensus on the antecedents and outcomes of entry mode choice (Datta, Herrmann \& Rasheed, 1997). One conceptual limitation of the research conducted so far is that it has given little attention to sociological approaches (Lu, 2002). Adding institutional variables to transaction cost approaches and resource-based approaches enhances our understanding of international entry mode choice since they refer to conditions that undermine property rights and increase risks in exchange (North, 1990).

Entry mode choice is a complex system of interacting elements. In such an intricate network of factors, cause, effect, and the timing at which they occur cannot be identified easily. It is difficult to see these relationships and to resolve important issues like transaction-cost, resource-based, and institutional approaches to entry mode. Companies are forced to contend with more problems than they have the resources to handle. To deal with the social, economic, and political issues faced upon entry in a new market, we need to order our priorities, to agree that one objective can outweigh another in the short term, and to make tradeoffs to serve the greatest common interest.

This research proposes a framework for entry mode choice to assist the group of shareholders, subordinates, peers, and superiors of a multinational enterprise (MNE) to have a consensus choice of one or more entry modes. The group decision framework comprises 11 possible stages. Analytical Network Process (ANP) is the major technique employed in the framework. We propose to employ ANP for entry mode choice since brainstorming and sharing ideas and insights often leads to better representation and understanding of the issues than would be possible for a single decision maker.

Companies are increasingly changing their decision processes, departing from authoritarian styles of management and developing systems to encourage individuals to participate in the decisions that affect them. Once a company had decided on foreign investment, each of the managers and shareholders should be involved in developing the criteria for determining the entry modes. This group decision empowers employees and shareholders to become active participants in shaping the environmental context of their company. This decision making process enables shareholders and employees to 
recognize the significance of their mutually dependent relationships and to value the perspectives of others involved in the foreign subsidiaries. Recognizing the need for shareholders, managers and employees at different levels of participation in the entry mode choice, we propose that shareholders and employees are able to influence decisions that ultimately affect them. Finally, a participative process is particularly desirable in the choice of entry modes because its success depends on acceptance by employees and shareholders.

Entry mode selection is an important and practical task for an enterprise when entering a foreign market. No method described in the literature can be applied directly. The case of a photoelectric lens company in Taiwan wanting to invest in Vietnam or Thailand has many of the characteristics of entry mode selection. ANP is a general theory of relative measurement that is used to composite-priority-ration scales from individual-ration scales to represent the differential influence of factors with respect to control determinants. Based upon the theories of Transaction Cost Economics and Institutional Approach, it is concluded that there are four major factors to compare: general transaction costs, asset specificity, internal environmental institutions, hostcountry environmental institutions, and the 12 indices embedded in them. Further, there are five modes of entry into Vietnam and Thailand: wholly owned subsidiary, joint venture, contract arrangement, direct exporting, and indirect exporting. The ANP model deals with the 11 interactions among the factors and 33 interactions among the indices. Because some portions of the data are inaccessible, the actual data was supplemented with hypothetical numbers to illustrate the processes. The objective of this research is to provide an applicable method for entry mode selection for companies entering foreign markets.

A group decision framework for the stakeholders of the company implementing an ANP model for selecting the entry modes is also illustrated.

\section{LITERATURE REVIEW}

The applications of Analytical Hierarchy Process (AHP) to entry mode choice are reviewed here. The literature relevant to the two major entry mode choice approachestransaction cost and institutional- is reviewed in Section 3 to support the ANP model developed here. A range of entry mode choice approaches exist. The approaches should not be limited. The choice of approaches should depend on the objectives of the individual company. 
The AHP framework, developed by Saaty (1980) has been identified as an important approach to multi-criteria decision-making. The AHP framework is well suited to individual and group decision making due to its role as a synthesizing mechanism. Dyer and Forman (1992) argue that the AHP, when used in a group setting. Bard and Sousk (1990) and Lai, Wong \& Cheung (2002) stated that the AHP provides data in an accessible format and provides a logical means of synthesizing judgment. Korpela and Tuominen (1996) argued that the AHP is an effective and flexible tool for group decision making.

Levary and Wan (1999) and Shih (2006) proposed an AHP model for selecting entry modes when a company seeks to invest in a foreign country. Wu \& Shih (2007) went on to report the framework of group choice for the AHP model.

\section{THE BASIS OF THE ANP ENTRY MODE SELECTION MODEL}

The determinants, indicators and entry mode alternatives that feature in the ANP model are discussed frequently in the international business literature.

\section{Determinant (A): General Transaction Costs (TC)}

The basic premise of the TC approach is that the governance structure a firm chooses for a given venture is driven by a desire to minimize transaction costs (Williamson, 1985). As the transaction costs increase, firms tend to switch their preference to modes with a greater deal of ownership, such as wholly owned subsidiaries (Brouthers, 2002; Taylor, Zou \& Osland, 1998; Erramilli \& Rao, 1993; Anderson \& Gatignon, 1986).

A given transaction may incur ex ante and ex post costs (Williamson, 1985). Ex ante costs include the costs of drafting, negotiating, and safeguarding a contract. Ex post costs are likely to arise due to the bounded rationality of decision makers, uncertainty, and complexity of the environment, and asymmetric distribution of information between parties to an exchange.

\section{Determinant (B): Asset specificity}

Asset specificity refers to the ease with which could be redeployed to alternative uses and by alternative users without loss of productive value(Williamson, 1985). Asset specificity tends to create and increase contracting hazards because of the impact of opportunism (Williamson, 1975; 1985). Opportunism results when a partner organization takes advantage of the other firm's dependency through shirking, free riding, or technology dissemination. To safeguard specific assets from potential 
opportunism problems, or more risk, firms may utilize higher control governance structures, such as wholly owned modes of entry (Brouthers, 2002; Lu, 2002; Delios \& Beamish, 1999).

Research and development (R\&D) intensity is a measure of a firm's possession of proprietary technological knowledge. There is a positive relationship between R\&D intensity and high control entry modes. Marketing intensity is a measure of a firm's possession of proprietary marketing assets (Hennart \& Park, 1993). The greater the marketing intensity in the foreign investing firm's assets, the greater the preference for high control modes of entry. According to Mutinelli and Piscitello (1998) and Tsai and Cheng (2002), the greater the specialist proportion in the foreign investing firm's assets, the greater the preference for high control modes of entry.

\section{Determinant (C): Internal environmental institutions}

The central premise of the institutional approach is that firms adopt structures and practices that are isomorphic pressures to those of the other firms as a result of their quest to attain legitimacy (Zucker, 1983). The degree of interdependency or resource sharing that occurs within the network of subsidiaries may cause firms to seek parent isomorphism. Relationships between a multinational's corporate headquarters and its subsidiaries are researched largely based on their interdependence, whether in capital flow, product and knowledge exchange (Gupta \& Govindarajan, 1991), cognitive frameworks (Ghoshal \& Bartlett, 1990) or human resources sharing (Boyacigiller, 1990). Relatively high degrees of resource sharing among the subsidiaries within an MNE would tend to result in subsidiaries achieving foreign market penetration using high control modes of entry, and would be more likely to coordinate their modes of entry and, thereby, reinforce internal isomorphism (Davis et al., 2000).

The autonomy granted to subsidiaries is a reflection of the reinforcement practices adopted by the parent organization (DiMaggio \& Powell, 1983). Subsidiaries with a low level of strategic autonomy are less likely to possess the authority to adopt resource deployment patterns that deviate from the norms of other intra-organizational units. It can be argued that a lack of autonomy would constrain subsidiaries in their selection of entry mode, and thereby in their ability to respond to variations in the host environment (Davis et al., 2000).

Scholars also suggest that the selection of foreign entry mode is influenced by isomorphic pressures embedded in internal operational environments, as well as by the cognitive limits of decision makers regarding this selection (Padmanabhan \& Cho, 1999; Yiu \& Makino, 2002). In other words, organizational historical and inertia 
factors lead to internal institutional persistence; that is, firms repeat what they have done in the past. As Yiu and Makino (2002) argue, an MNE will follow the mode of entry that has been used most frequently in the same host country in the past; that is, internal mimicry-historical norm.

\section{Determinant (D): Host-country environmental institutions}

Institutional theorists argue that a major driving force behind organizational activities is a firm's desire to fit with its external institutional environment by conforming to institutional pressures from the host country (Martinez and Dacin, 1999). Selection of foreign market entry mode should focus on adaptation to host country market characteristics, such as political stability, economic fluctuation, government mandates, local market potential, socio-cultural differences, and the general business conditions of the local market (Davis et al., 2000; Kogut \& Singh, 1988).

First, host country's political and economic risks have received the most attention in conceptual and empirical studies of entry mode selection. In international operations that are characterized by an uncertain and volatile environment from host country risk, firms are better off utilizing low control ownership modes (Delios \& Beamish, 1999; Erramilli \& Rao, 1993).

Second, the local market's potential in terms of its current size and growth potential have been found having influence foreign market entry mode (Brouthers, 2002; Agarwal \& Ramaswami, 1992). A large market potential may presage strong sales and profit, thus motivating entry into foreign markets (Shama, 2000). Past research suggests that in high growth markets firms tend to prefer wholly owned modes of entry so they can obtain scale economies to reduce per unit costs and establish a long-term market presence (Agarwal \& Ramaswami, 1992). In slow growth markets, firms may find that low control modes provide better opportunities either because they do not increase the capacity in the market, or can provide a better return on investment by minimizing the resource commitment, or reduce the switching costs of exiting the market if product/service sales are low (Brouthers, 2002).

Third, socio-cultural institutions are important determinants of the host country environment, representing differences between the market entrant's home country and the local market in terms of business practices and norms as well as social culture (Brouthers, 2002; Erramilli \& Rao, 1993). There are conflicting views in the entry mode literature concerning the impact of socio-cultural distance. The first, when socio-cultural distance is great, low-control entry modes are more efficient (Anderson \& Gatignon, 1986; Kogut \& Singh, 1988). Low socio-cultural distance reduces the need to invest in 
information, to train local staff and to adapt management processes to the local environment. This affects all forms of business, but to varying degrees (Oxley, 1999). The second, other research suggests that some firms react to socio-cultural distance by demanding rather than avoiding ownership so that they may impose their operating methods. Such firms do not trust local management or non-local partners and prefer the high-control entry mode (Anderson \& Gatignon, 1986).

Fourth, scholars empirical evidence has found support for the fact that firms imitate the practices adopted by a large number of firms and that firms base their selection of role models upon certain traits such as firm size and status (Haunschild \& Miner, 1997). MNEs will tend to use a follow-the-leader approach and follow the dominant entry mode chosen by their home-country incumbents in the same host country (Yiu \& Makino, 2002).

\section{Alternatives of Entry modes}

Modal selection is a tradeoff between costs and benefits (Erramilli \& Rao, 1993). Entry modes vary significantly in terms of not only costs incurred by firms but also benefits provided to firms. Most frameworks of entry mode selection tend to agree with each other on the cost side. Generally export and non-equity modes are perceived to cost less, and joint ventures and wholly owned subsidiaries are perceived to cost more. Frameworks differ from each other significantly in the way that they assess the nature of benefits provided by the modes. In the transaction cost approach the benefit sought is the reduction of transaction costs, while in the institutional approach the benefit sought is the adaptation to environmental pressures and the quest for legitimacy because a firm is embedded in both its own internal institutional environment and the external institutional environment.

Different entry modes imply different levels of control and integration with the foreign operation (Anderson \& Gatignon, 1986). Control refers to authority over operational and strategic decision-making to reduce transaction costs. On the other hand, different entry modes also imply different levels of adaptation and risk for the foreign operation. In choosing a particular entry mode, a company constructs a fit between its needs for internal corporate strategy and the externally perceived risk and adaptation level of the target entry market. Two companies may perceive different risks and degrees of adaptation as they evaluate the same market under their own strategy. Therefore, they may easily choose different entry modes. General speaking, there are five basic strategies for entering a new market: indirect exporting, direct exporting, contractual arrangement, joint venturing, and wholly owned subsidiaries. 
According to this paper defines an entry mode as a way of organizing a firm's activities in a foreign country that allows an MNE to have tradeoff between costs and benefits and to implement its "appropriate" entry strategy through indirect exporting, direct exporting, contractual arrangement, joint ventures, and wholly owned subsidiaries in the host country. The "appropriate" entry mode then can be defined as the strategy that best minimizes transaction costs and can best adapt to pressures from both internal and external institutions.”

\section{GROUP DECISION FRAMEWORK FOR ENTRY MODE CHOICE}

The proposed group decision framework for an MNE to have consent over entry mode choice is illustrated in Figure 1, which comprises 11 possible stages.

\section{Form a task force team}

Stage 1 is to form a task force (TF) unit to execute the administration work of the chosen entry mode. One or several individuals who are experts in international business, specifically of the chosen entry mode choice, should participate in the TF. The experts may be employees of the MNE or hired consultants specific to the foreign investment project. The experts should fully understand the MNE in terms of goal, strategy, structure, and operation since choosing the entry mode choice is strongly connected to strategy.

\section{Form a decision making group}

In Stage 2, the MNE forms a decision-making group (DMG) that includes shareholders, CEO, president, finance manager, marketing manager, R\&D manager, legal advisor, production manager, employee representatives, stakeholders, and individuals related to the foreign subsidiaries. Most companies, however, still neglect to include employees and stakeholders in decisions that influence the ability to perform their professional practices and investment desires, respectively. The participants are called 'judges' in this paper. 


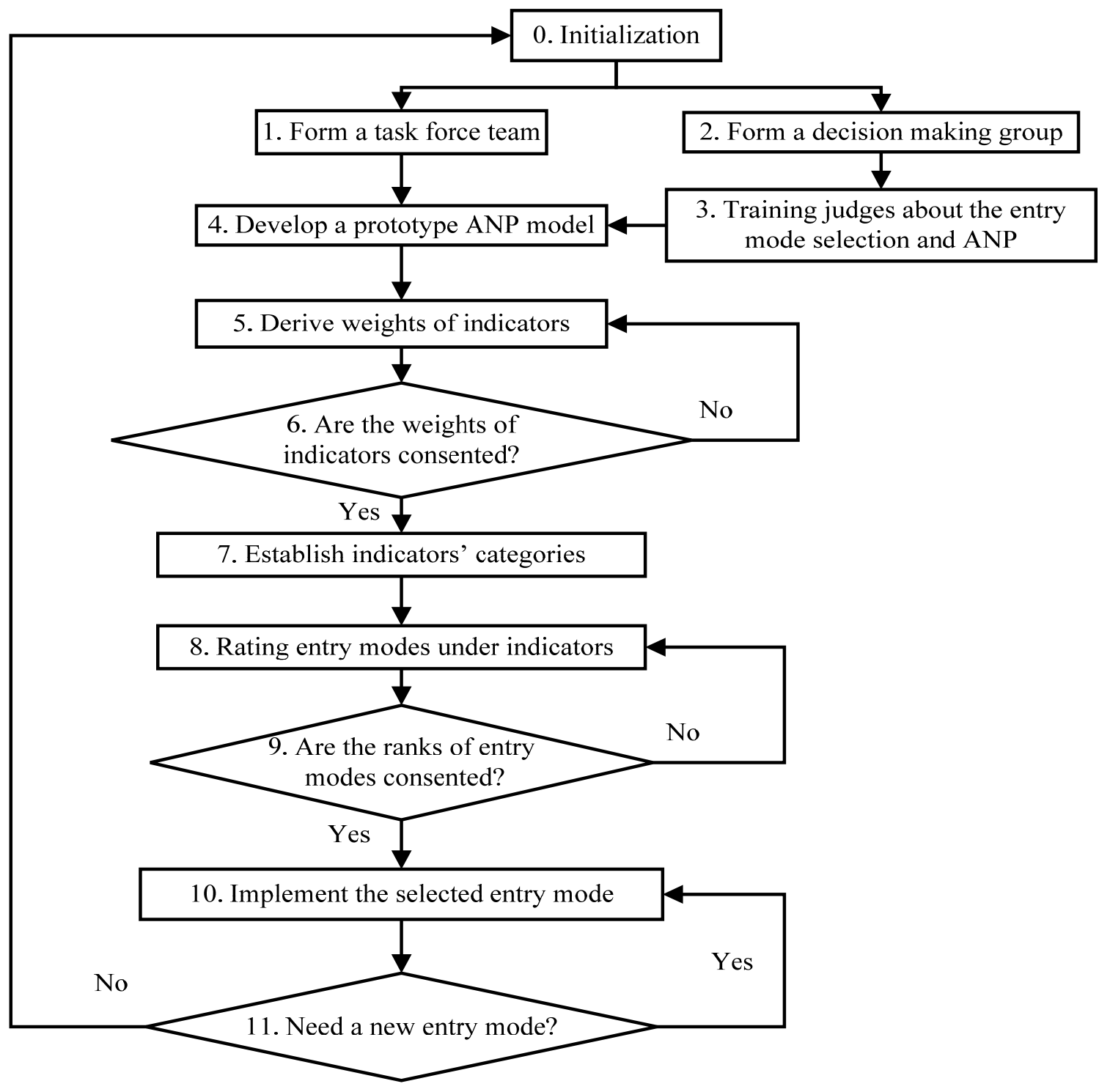

Figure 1 Group decision framework for an MNE to have a consensus entry mode choice

\section{Training Judges about the entry mode selection and ANP}

The CEO, President, and managers of the company are involved in Stage 3, which involves the construction of a prototype Analytical Network Process (ANP) model. Group members could refer to the hierarchy of detailed EMS levels. Suggestions are offered here for conducting EMS with a group. First, make sure the participants are well provided with materials and resources about EMS. In the first group session, explain how the ANP works with simple applications. Allow for a question-and-answer period. Then, a group session that has two discussion leaders with one or two assistants begins by reviewing the proposed model, as depicted in Figure 2 and the definitions of the 
elements as presented in Section 3 of this paper. The participants should be well informed, highly motivated, and in agreement on the basic question being addressed.

In the beginning, the experts have meetings with the CEO, President, and executers of the MNE to understand the company's mission at the strategic level. The experts also have meetings with the managers to discuss tactics in relation to finance, marketing, R\&D, legal issues, and production. Depending on the subject, one or more than one manager may be invited to attend each meeting. While many companies are convinced of the need for such participatory decision processes for entry mode choice, they realize it is difficult to implement the process because stakeholders, shareholders, and employees often lack the necessary training and experience in foreign investment. Even experienced managers need assistance in considering the multiplicity of criteria relevant to entry mode choice. A participatory process complicates the matter further because one must also decide how to weigh and aggregate the opinions and judgments of so many participants. For evaluating the usefulness of a participant to engage in the decision process, first, managers are given a background questionnaire on their experience with multi-criteria decision problems, and their knowledge of multi-criteria methods. Second, the judges are given a lecture on AHP/ANP methodologies. The experts provide the relevant choice information and reports to the managers. They then analyze these reports prior to the meeting where their perspectives on entry mode considerations are discussed.

\section{Develop a prototype ANP model}

The objective of Stage 4 is to demonstrate that an ANP model incorporating the majority of determinants from prior studies can be used to select entry modes for a company that plans to invest in a foreign country. Explicitly, the model must account for the two major theories in entry mode selection: Transaction Cost Economics and Institutional Approach. Moreover, it would be useful to include a conceptual range of "all possible" determinants and indicators of entry mode selection into this model, even if some rarely occur and might not show up as statistically significant.

The model proposed here incorporates four determinants, their elements and the connection between them. The control cluster is illustrated in Figure 2. The arrows indicate the direction of causal impact with the looped arrow indicating feedback effects. For example, in the Internal Environmental cluster, it is assumed that an impact from " $\left(\mathrm{C}_{1}\right)$ the degree of interdependency or resource sharing among the MNE and subsidiaries" will impact " $\left(\mathrm{C}_{2}\right)$ internal mimicry entry resulting from the historical norm”. 
Although these indicators are generic enough to cover most companies' entry modes selection, there would be a need to customize the sub-indicators for a specific company to enter a foreign market. Once the characteristics of the model have been specified, then the TFs must provide judgments on the relative importance of those various indicators in the model as they relate to the system's alternatives. In this case, five entry modes are considered for Vietnam and Thailand: $\left(E_{1}\right)$ wholly owned subsidiary in Vietnam, $\left(E_{2}\right)$ joint venture in Vietnam, $\left(E_{3}\right)$ contractual arrangement in Vietnam, $\left(E_{4}\right)$ direct export to Vietnam, $\left(E_{5}\right)$ indirect export to Vietnam, $\left(E_{6}\right)$ wholly owned subsidiary in Thailand, $\left(E_{7}\right)$ joint venture in Thailand, $\left(E_{8}\right)$ contractual arrangement in Thailand, $\left(E_{9}\right)$ direct export to Thailand, and $\left(E_{10}\right)$ indirect export to Thailand.

The evaluation criteria in the decision hierarchy are comprehensive and relevant for entry mode evaluation. The objective, determinants, indicators and alternatives are expressed in fairly general terms and can be understood by all managers.

The judges can then provide opinions on each element of the model as depicted in Figure 2, debate the judgments and make a case for their values until consensus or compromise is reached. The entry mode found to be the best for one company is not necessarily the best for a different company operating in the same country. Accordingly, the methodology employed for choosing an entry mode must consider the unique characteristics of a particular company. Risks unique to the entry mode under consideration along with input from the company's management must be considered if the decision is to be realistic. The process of group interaction cannot be reduced to a set of rules. Broadening people's views and stimulating their thinking and retaining flexibility are all-essential to entry mode choice.

A "top-down" way of thinking can be used to guide the modification of the ANP model. From this perspective, participants gain a broader understanding of the decision problem and design a better and more integrated decision hierarchy to contribute to better decisions. At the end of the fourth stage, the prototype ANP model is modified.

\section{Calculate the weights of indicators}

In Stage 6, judges perform the steps to weigh the importance of different indicators. TFs help judges to perform pair wise comparisons and collect the data to derive the priorities of items by the DMG. If the participants obtained a consensus in Stage 5, it is then possible to proceed to Stage 6. Otherwise, it is necessary to return to Stage 5. The TF may employ the Delphi method to modify the ANP model in this situation. 
There are four major steps for Stage 5.

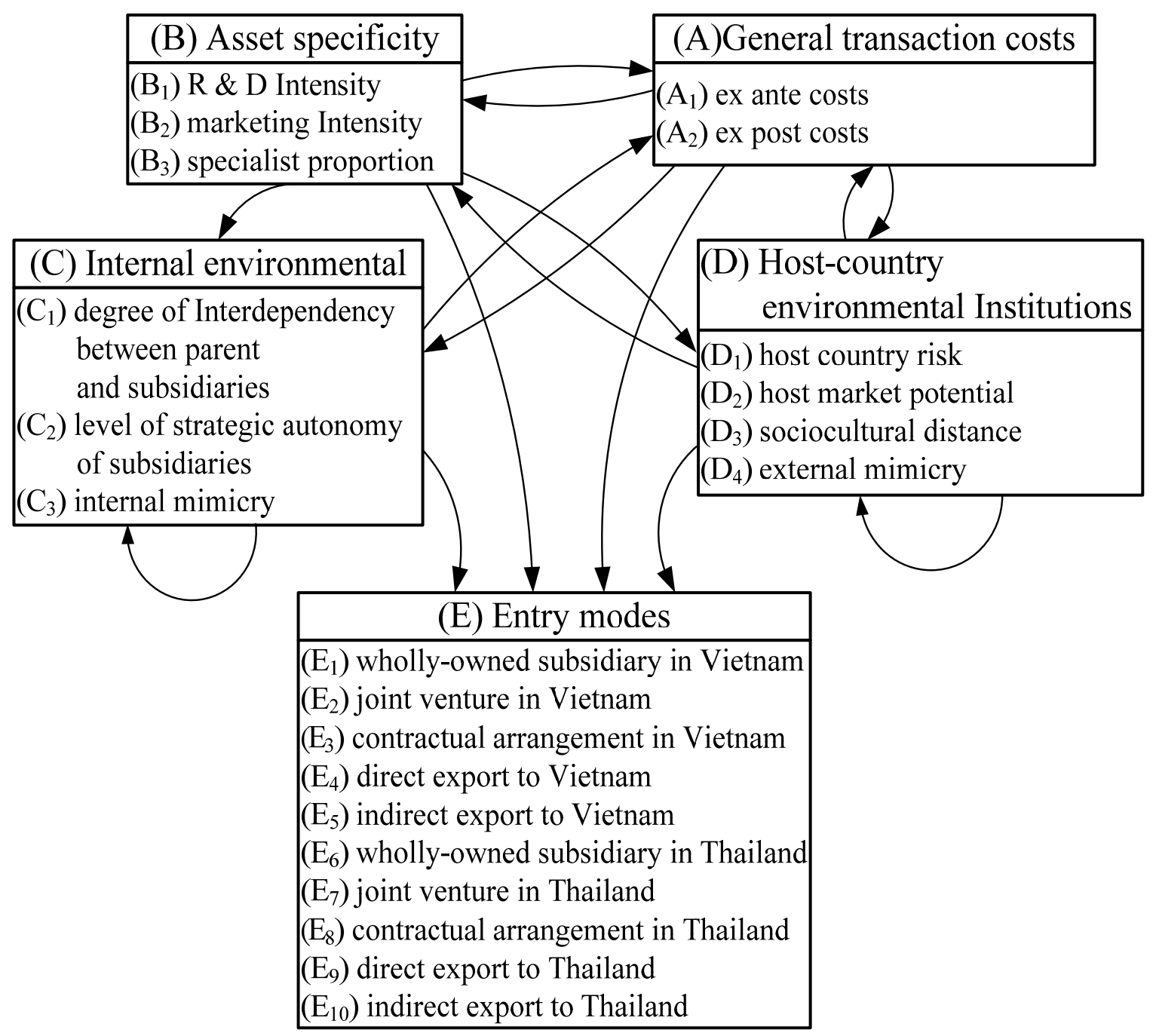

Figure 2 Overview: the ANP-network entry mode selection model's control hierarchy

\section{- Step 1: each judge determines the main cluster weights}

The main or control cluster weights for $\{A, B, C, D\}$ are determined based on: (1) whether there is feedback in the cluster (if not, the matrix entry is zero), and (2) the intensity of relationship between the cluster and other clusters using the nine point scale. To illustrate the development of the main cluster weights in our model, first observe that (A) and (B) clusters do not include feedback (Figure 2). Consequently, the entries for both clusters in the control matrix are zero. On the other hand, (C) and (D) clusters are modeled with feedback given that those indicators can spiral in upon 
themselves. This means an average effect must be assessed akin to using the 'dynamic multiplier' in stochastic modeling and cutting off the cumulative effect at any specific point in time. Each judge should complete the four comparison matrices respects to A, $\mathrm{B}, \mathrm{C}$, and $\mathrm{D}$. The components in the matrices are BCD, ACD, AC, and ABC, respectively. The judge should redo the comparisons if the derived priorities show an unacceptable consistency ratio. With respect to (B), for example, a pair-wise comparison of (A) compared with (C) might be assigned a score in the control matrix of ' 3 ,' which would mean that determinant (A) is very likely to impact (B) relative to (C). These ratings, demonstrated here as judgmental scores, incorporate "existing knowledge" about the economic landscape from various information sources. Each score encompasses two aspects of the entry mode selection process into one evaluation measure: (a) the significance of the cluster or economic process relative to the overall stated objective, and (b) the current importance of that determinant. Although the former aspect may be relatively stable over time, the latter evaluation criterion will clearly change.

\section{- Step 2: Derive the main cluster weights of judges}

Every judge completed the four comparison matrices in Step 1. TF computes the geometric mean of each cell in the four matrices. Then, the eigenvector solution of each matrix is derived using the standard application of AHP. The four eigenvectors are then arranged into the columns of the control matrix, as shown in Equation (1).

$$
M^{\text {Control }}=\begin{array}{cccc}
A & B & C & D \\
& B \\
C \\
D
\end{array}\left[\begin{array}{llll}
w_{A A} & w_{A B} & w_{A C} & w_{A D} \\
w_{B A} & w_{B B} & w_{B C} & w_{B D} \\
w_{C A} & w_{C B} & w_{C C} & w_{C D} \\
w_{D A} & w_{D B} & w_{D C} & w_{D D}
\end{array}\right]
$$

\section{- Step 3: Determine the scores of indicators cross the clusters}

The ANP provides the mathematical framework for our model to aid in the selection of an entry mode using heuristics. Conceptually, the entry mode selection model can be described as a system of four components (which may be part of a cluster of components) that forms a network where every component (A, B, C, D) can interact or have an influence on itself or some or all of the other components of the system. A super matrix, $M^{\text {initial-super }}$, is a complete system matrix of components 
$\{$ A, B, C, D $\}$, and their linkages or system weights, $M_{i j}$, where $V_{A}=\left\{A_{1}, A_{2}\right\}, V_{B}=$ $\left\{B_{1}, B_{2}, B_{3}\right\}, V_{C}=\left\{C_{1}, C_{2}, C_{3}\right\}$, and $V_{D}=\left\{D_{1}, D_{2}, D_{3}, D_{4}\right\}$ are the subcomponent indicators of the factor components $\mathrm{A}, \mathrm{B}, \mathrm{C}$ and $\mathrm{D}$, respectively. ANP allows interaction and feedback within components, A, B, C and D, which are known as inner dependence, and between factors, which are known as outer dependence. To make it more concrete, if there is no linkage between, say $C$ feeds to $D$ then $W_{D C}$ would be zero. However, if there is some relationship, then the entry would be nonzero, suggesting an outer dependence. An inner dependence would exist if there were a linkage within the subcomponent indicators of a factor component.

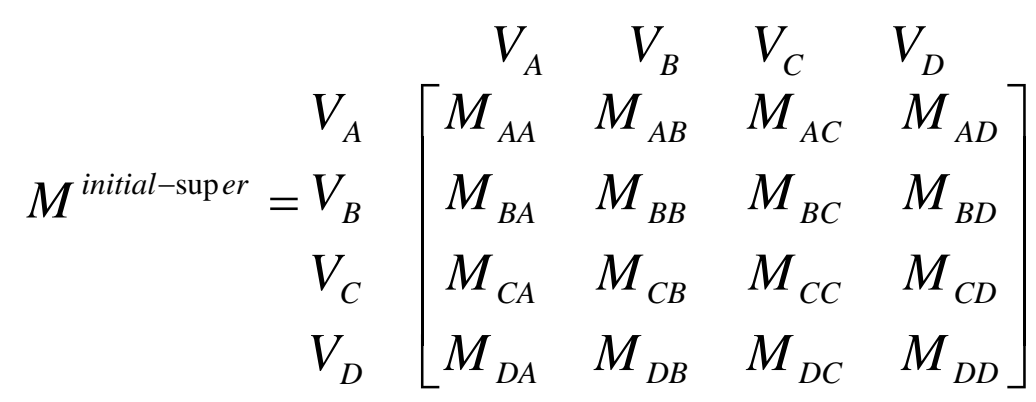

The model weights within each cluster, $\left\{A_{1}, A_{2}\right\},\left\{B_{1}, B_{2}, B_{3}\right\},\left\{C_{1}, C_{2}, C_{3}\right\}$, and $\left\{D_{1}, D_{2}, D_{3}, D_{4}\right\}$, are derived using the standard application of pair wise comparison in AHP (Saaty, 2001). For example, in Figure 2, an arrow projects from cluster (B) to cluster (A) highlighting that each indicator in cluster (B) has a casual relationship with the indicator in cluster $(A)$. Each judge should complete the three comparison matrices respect to indicator $\mathrm{B}_{1}, \mathrm{~B}_{2}$ and $\mathrm{B}_{3}$. The components in the matrices are $A_{1}$ and $A_{2}$. The judge should redo the comparisons if the derived priorities show an unacceptable consistency ratio. TF then computes the geometric mean of all the judges for each cell in the three matrices. The eigenvector solution for each geometric mean matrix is derived by using the standard application of AHP. The three eigenvectors are then arranged into the columns of matrix $M_{A B}$, as shown in Equation (3). All other sub-matrices in $M^{\text {initial-super }}$ should be compeleted as the same manner.

$$
\begin{gathered}
B_{1} \\
M_{A B}=A_{1} \\
A_{2}
\end{gathered}\left[\begin{array}{ccc}
W_{A 1 B 1} & W_{A 1 B 2} & W_{A 1 B 3} \\
W_{A 2 B 1} & W_{A 2 B 2} & W_{A 2 B 3}
\end{array}\right]
$$




\section{-Step 4: Construct and solve the super matrix}

Each sub-matrix of $M^{\text {initial-super }}$ is then multiplied by the priority weights corresponding to the cell in matrix $M^{\text {Control }}$. For instance, for the sub-matrix $M_{A B}$, as shown in equation (2), all the elements are multiplied by the corresponding value in equation (1), $w_{A B}$. The same process should be performed for all sub-matrices in the initial-super matrix to yield the weighted super matrix as illustrated in Equation (4). This is necessary because a matrix must be stochastic, that is, its columns must add up to one.

$$
\begin{gathered}
M^{\text {Weighted-Super }}= \\
V_{A} \\
V_{B} \\
V_{C} \\
V_{D}
\end{gathered}\left[\begin{array}{lllll}
M_{A A} * w_{A A} & M_{A B} * w_{A B} & M_{A C} * w_{A C} & M_{A D} * w_{A D} \\
M_{B A} * w_{B A} & M_{B B} * w_{B B} & M_{B C} * w_{B C} & M_{B D} * w_{B D} \\
M_{C A} * w_{C A} & M_{C B} * w_{C B} & M_{C C} * w_{C C} & M_{C D} * w_{C D} \\
M_{D A} * w_{D A} & M_{D B} * w_{D B} & M_{D C} * w_{D C} & M_{D D} * w_{D D}
\end{array}\right]
$$

The super matrix represents the impact of all entry mode indicators relative to the complete indicator set. However, each column of the super matrix itself may include several sub-columns with its own priority indicator element, which must be normalized and synthesized to account for the overall factors' influence by columns. This process makes the super matrix column stochastic. The final priority weights, which account for indicator interactions, are derived by multiplying the super matrix by itself until the columns stabilize, which occurs when the super matrix entries become identical across each row, and the result is known as the limiting matrix. The final priority weights are extracted from this limiting matrix. Our numerical example had the weights of indicators depicted in Table 1.

\begin{tabular}{|c|c|c|c|c|c|c|c|c|c|c|c|c|c|}
\hline & A & & & & & $\mathrm{B}_{3}$ & $\mathrm{C}_{1}$ & $\mathrm{C}_{2}$ & $\mathrm{C}_{3}$ & $\mathrm{D}_{1}$ & $\mathrm{D}_{2}$ & $\mathrm{D}_{3}$ & $\mathrm{D}_{4}$ \\
\hline & & & & & & 0.079 & 0.033 & 0.032 & 0.040 & 0.092 & 0.088 & 0.087 & 0.055 \\
\hline
\end{tabular}

Table 1 Weights of indicators obtained from limiting super matrix

As the weights of indicators are obtained, the judges are asked if they have any concerns. The judges should articulate their criteria and ensure that each of their weights and preferences are internally consistent. They might identify why their individual ratings of determinants and indicators are so different from the ratings of the DMG. This feedback then makes the TF aware of the limitations of ANP ingroup decision making. While ANP ensures that each individual judge is internally 
consistent in making judgments, it does nothing to ensure the sharing of certain judgments, or to ensure a degree of consistency within a group of judges. Furthermore, ANP does not guarantee that group consensus will prevail in the ranking of the determinants and indicators.

\section{Is there consensus on weights of indicators?}

In Stage 6, DMG needs to identify the weights of the determinants and indicators. First, individual judgments should be revised in view of anonymous group feedback derived from the Delphi technique (Dalkey \& Helmer, 1963). While there have been many variations in practice (Malhotra, Steele \& Grover, 1994), the Delphi method consists of three essential processes to achieve information exchange among a group of judges without introducing the potential biases of interpersonal interaction. The first process is to collect judgment, along with the underlying rationales, from individuals who are knowledgeable about an issue, by questioning them individually. The second process is to collate and statistically summarize the individual judgments and rationales without revealing the identity of the individuals. The third process is to feed the collated information back to individual judges and revise their judgments, as necessary. This sequence of collating, feedback, and revision is repeated over several rounds until further repetitions produce negligible changes in individual judgments.

\section{Establish indicators' categories}

In Stage 7, each judge casts a ballot for his entry mode of preference with respect to each indicator. TFs collect judges' ballots, then calculate the scores by the weights of indicators, and take the sum of all indicators. The result is the overall score of the ANP model.

At this point, TF presents the results to the judges and then ask them if they have any concerns. To use the AHP method, the decision group first determines an appropriate number of categories for each indicator. Each judge performs a pair wise comparison of categories for each indicator. For example, the standards for the indicator $\mathrm{B}_{2}$ are Extreme, Great, Significant, Moderate and Tad. Judgments are entered for questions such as "How much more preferable is extreme than great for this indicator?" or "How much more preferable is significant than moderate for this indicator?" 


\section{Rating entry modes under indicators}

Absolute scales for each indicator have been established. In this step, entry modes are rated one at a time by selecting the appropriate category under each indicator rather than compared against other entry modes. In absolute measurement, the entry modes are scored independently of each other. In relative measurement, there is dependence, as an entry mode's performance depends on what other entry modes there are in the comparison pool.

The average ratings of the 20 judges for each entry mode under each indicator are summarized in Table 2.

Table 2 Average scores of entry modes under indicators

\begin{tabular}{rrrrrrrrrrrrrrrr}
\hline & $\mathrm{A}_{1}$ & $\mathrm{~A}_{2}$ & $\mathrm{~B}_{1}$ & $\mathrm{~B}_{2}$ & $\mathrm{~B}_{3}$ & $\mathrm{C}_{1}$ & $\mathrm{C}_{2}$ & $\mathrm{C}_{3}$ & $\mathrm{D}_{1}$ & $\mathrm{D}_{2}$ & $\mathrm{D}_{3}$ & $\mathrm{D}_{4}$ & Scr. & Nrml. & Rnk. \\
\hline $\mathrm{E}_{1}$ & 0.60 & 0.70 & 0.78 & 0.31 & 0.56 & 0.73 & 0.76 & 0.46 & 0.54 & 0.28 & 0.24 & 0.37 & 0.54 & 0.867 & 9 \\
\hline $\mathrm{E}_{2}$ & 0.64 & 0.76 & 0.59 & 0.41 & 0.41 & 0.52 & 0.61 & 0.86 & 0.75 & 0.44 & 0.35 & 0.81 & 0.60 & 0.964 & 2 \\
\hline $\mathrm{E}_{3}$ & 0.82 & 0.58 & 0.47 & 0.70 & 0.41 & 0.31 & 0.33 & 0.71 & 0.57 & 0.62 & 0.72 & 0.44 & 0.59 & 0.936 & 4 \\
\hline $\mathrm{E}_{4}$ & 0.72 & 0.65 & 0.85 & 0.48 & 0.59 & 0.43 & 0.53 & 0.42 & 0.38 & 0.51 & 0.36 & 0.33 & 0.57 & 0.905 & 7 \\
\hline $\mathrm{E}_{5}$ & 0.78 & 0.39 & 0.63 & 0.71 & 0.50 & 0.24 & 0.26 & 0.49 & 0.74 & 0.79 & 0.50 & 0.48 & 0.58 & 0.917 & 6 \\
\hline $\mathrm{E}_{6}$ & 0.65 & 0.64 & 0.69 & 0.37 & 0.74 & 0.65 & 0.75 & 0.35 & 0.66 & 0.55 & 0.61 & 0.74 & 0.63 & 1.000 & 1 \\
\hline $\mathrm{E}_{7}$ & 0.72 & 0.67 & 0.79 & 0.43 & 0.24 & 0.42 & 0.52 & 0.75 & 0.65 & 0.43 & 0.47 & 0.59 & 0.59 & 0.938 & 3 \\
\hline $\mathrm{E}_{8}$ & 0.84 & 0.51 & 0.81 & 0.69 & 0.54 & 0.26 & 0.37 & 0.67 & 0.51 & 0.58 & 0.42 & 0.33 & 0.59 & 0.933 & 5 \\
\hline $\mathrm{E}_{9}$ & 0.60 & 0.56 & 0.58 & 0.34 & 0.75 & 0.45 & 0.59 & 0.42 & 0.37 & 0.32 & 0.24 & 0.66 & 0.50 & 0.797 & 10 \\
\hline $\mathrm{E}_{10}$ & 0.75 & 0.36 & 0.69 & 0.75 & 0.43 & 0.23 & 0.27 & 0.38 & 0.76 & 0.65 & 0.32 & 0.63 & 0.55 & 0.875 & 8 \\
\hline
\end{tabular}

\section{Are the ranks of entry modes consented?}

In Stage 9, the entry mode score is obtained by weighting the selected category by the priority of the indicator and calculating the sum of all the indicators. The right hand side of Table 2 lists total scores and ranks. Then the information is collated to individual judges and a revision of their judgments is sought, as necessary. This sequence of collating, feedback, and revision is repeated over several rounds until further repetitions produce practically no changes in individual judgments. The outcome of this process was that $\left(\mathrm{E}_{6}\right)$ Wholly-Owned Subsidiaries in Thailand produced the highest rank. Judges may vote on the top three entry modes - $\left(E_{6}\right),\left(E_{7}\right)$, and $\left(E_{2}\right)$ or others to make the final selection.

\section{Implement the selected entry mode}

Stage 10 consists of the company implementing the selected entry mode. 


\section{Performance review}

In Stage 11, the company periodically reviews the performance of the selected entry mode. It may return to Stage 1 to repeat the entire process if a new entry mode is needed.

\section{CONCLUSIONS}

As shown in Table 1, $\left(\mathrm{A}_{2}\right)$ Ex post costs, $\left(\mathrm{A}_{1}\right)$ Ex ante costs and $\left(\mathrm{B}_{1}\right)$ Research and Development $(R \& D)$ Intensity have the three highest weights, $0.181,0.18$, and 0.124 , respectively. On the other hand, $\left(C_{1}\right)$ The degree of interdependency or resource sharing between the MNE and subsidiaries, $\left(\mathrm{C}_{2}\right)$ The degree of autonomy of subsidiaries, and $\left(\mathrm{C}_{3}\right)$ Internal Mimicry Entry resulting from historical norm carry the three lowest weights, $0.033,0.032$, and 0.04 , respectively. One may delete some of the indices with low weights and redo the entire process.

In Table 2 shows $\left(E_{6}\right)$ wholly owned subsidiary in Thailand and $\left(E_{2}\right)$ joint venture in Vietnam are two highest final scores, 0.63 and 0.60 . Normalize the final scores by the highest score 0.63 , one would observe the normalized scores. The largest three scores, $1.0,0.964$, and 0.938 seems very close. One may modify some of the data to have the sensitivity for the final ranking of the entry modes.

This paper has presented a multiple criteria decision-making model incorporating a feedback mechanism to aid in the selection of entry modes for companies entering a foreign market using Saaty's Analytic Network Process as a foundation. ANP offers a selection structure that allows judges to evaluate entry modes in a consistent manner. This study found that the ANP model approach was indeed a promising methodology to assist in selecting an entry mode for entry into a foreign market.

This paper considers two countries only with five entry modes. For the cases of there are several countries under consideration, two phases approach is suggested. One may perform the ANP in the first phase to evaluate those countries only. In the second phase, the five entry modes or more could be evaluated by ANP. This two-phase approach would reduce the possible number of combinations from countries and entry modes for selection.

We use computer software Excel-Microsoft Office to compute the data. Each pair comparison in the steps uses a spreadsheet. The control matrix and initial-super matrix are generated by copy the weights that computed in every associated spreadsheet. Excel computes the data instantly for considerable large problems. The author would like to share the software as requested through the shown e-mail address.

This model employs the transactions cost approach and the institutional 
approach. Resource-based explanations may also be added to the ANP entry mode selection model. The model could be applied to other problems with qualitative characteristics for group-decision making. To illustrate the procedure, we used simulated data. A considerable number of pair wise comparison matrices are needed in the whole procedure. Each matrix needs to be consistent among its elements. This could be a challenge task to obtain the result and for further sensitivity analysis. The network expression, as shown in Figure 2, is subject to modified as the decision group's consensuses.

\section{REFERENCES}

Agarwal, S. \& Ramaswami, S. N. (1992). Choice of foreign market entry mode: impact of ownership, location and internalization factors. Journal of International Business Studies, 23(1), 1-28.

Anderson, E. \& Gatignon, H. (1986). Modes of foreign entry: a transaction cost analysis and propositions. Journal of International Business Studies, 17(3), 1-26.

Bard, J. F. \& Sousk, S. F. (1990). A tradeoff analysis for rough terrain cargo handlers using the AHP: an example of group decision making. IEEE Transactions on Engineering Management, 37(3), 222-229.

Boyacigiller, N. (1990). The role of expatriates in the management of interdependence, complexity and risk in multinational corporations. Journal of International Business Studies, 21(3), 357-382.

Brouthers, K. D. (2002). Institutional, cultural and transaction cost influences on entry mode choice and performance. Journal of International Business Studies, 33(2), 203-221.

Dalkey, N. \& Helmer, O. (1963). An experimental application of the Delphi method to the use of experts. Management Science, 9(3), 458-468.

Datta, D. K., Herrmann, P. \& Rasheed, A.. (1997). Antecedents and consequences of foreign market entry: what do we know? Paper presented at the Academy of International Business 1997 Annual Meeting, Monterrey, Mexico.

Davis, P. S., Desai, A. B. \& Francis, J. D. (2000). Mode of international entry: An isomorphism perspective. Journal of International Business Studies, 31(2), 239258.

Delios, A. \& Beamish, P. W. (1999). Ownership strategy of Japanese firms: transactional, institutional, and experience influences. Strategic Management Journal, 20, 915-933. 
DiMaggio, P. J. \& Powell, W. W. (1983). The iron cage revisited: institutional isomorphism and collective rationality in organizational fields. American Sociological Review, 48(1), 147-160.

Dyer, R. F. \& Forman, E. H. (1992). Group decision support with the analytic hierarchy process. Decision Support Systems, 8(2), 99-125.

Erramilli, M. K. \& Rao, C.P. (1993). Service firms' international entry-mode choice: a modified transaction-cost analysis approach. Journal of Marketing, 57, 19-38.

Ghoshal, S. \& Bartlett, C. (1990). The multinational corporation as an interorganizational network. Academy of Management Review, 15(4), 235-254.

Gupta, A. \& Govindarajan, V. (1991). Knowledge flows and the structure of control within multinational corporations. Academy of Management Review, 16(4), 768792.

Haunschild, P. R. \& Miner, A. S. (1997). Modes of interorganizational limitation: the effect of outcome salience and uncertainty. Administrative Science Quarterly, 42, 472-499.

Hennart, J. F. \& Park, Y. R. (1993). Greenfield vs. acquisition: the strategy of Japanese investors in the United States. Management Science, 39(9), 1054-1070.

Korpela, J. \& Tuominen, M. (1996). Benchmarking logistics performance with an application of the analytic hierarchy process. IEEE Transactions on Engineering Management, 43(3), 323-333.

Kogut, B. \& Singh, H. (1988). The effect of national culture on the choice of entry mode. Journal of International Business Studies, 19(3), 411-432.

Lai, V. S., Wong, B. K. \& Cheung, W. (2002). Group decision making in a multiple criteria environment: a case using the AHP in software selection. European Journal of Operational Research, 137(1), 134-144.

Levary, R. R. \& Wan, K. (1999). An analytic hierarchy process based simulation model for entry mode decision regarding foreign direct investment. Omega, 27, 661-677.

Lu, J. W. (2002). Intra- and inter-organizational imitative behavior: institutional influences on Japanese firms' entry mode choice. Journal of International Business Studies, 33(1), 19-37.

Makino, S. \& Beamish, P. W. (1998). Performance and survival of joint ventures with non-conventional ownership structures. Journal of International Business Studies, 29(4), 797-818.

Malhotra, M. K., Steele, D. C. \& Grover, V. (1994). Important strategic and tactical manufacturing issues in the 1990s. Decision Sciences, 25(2), 189-215. 
Martinez, R. J. and Dacin, T. M. (1999). Efficiency Motives and Normative Forces: Combining Transaction Costs and Institutional Logic. Journal of Management, 25(1), 75-96.

Mutinelli, M. \& Piscitello, L. (1998). The entry mode choice of MNEs: an evolutionary approach. Research Policy, 27(5), 491-506.

North, D.C. (1990). Institutions, institutional change and economic performance, Cambridge. UK: Cambridge University Press.

Oxley, J.E. (1999). Institutional environment and the mechanisms of governance: the impact of intellectual property protection on the structure of inter-firm alliance. Journal of Economic Behavior and Organization, 24, 283-310.

Padmanabhan, P. \& Cho, K. R. (1999). Decision specific experience in foreign ownership and establishment strategies: evidence from Japanese firms. Journal of International Business Studies, 30(1), 25-42.

Saaty, T. L. (1980). The analytic hierarchy process. NY: McGraw-Hill.

Saaty, T. L. (2001). Decision making with dependence and feedback: the analytic network process. Pittsburgh. PA: RWS Publications.

Shama, A. (2000) Determinants of entry strategies of U.S. companies into Russia, the Czech Republic, Hungary, Poland, and Romania. Thunderbird International Business Review, 42(6), 651-676.

Shih, S. (2006). A decision model regarding foreign direct investment. Journal of Technology Management, 11(2), 127-154 (in Chinese).

Taylor, C. R., Zou, S. \& Osland, G. E. (1998). A transaction cost perspective on foreign market strategies of US and Japanese firms. Thunderbird International Business Review, 40(4), 389-412.

Tsai, M. T. \& Cheng, Y. M. (2002). The decision criteria for the ownership control entry mode for Taiwanese manufacturing firms in the United States: an application of the Logit model and AHP. International Journal of Commerce and Management, 12(2), 45-71.

Williamson, O. E. (1975). Market and hierarchies: analysis and antitrust implications. New York, NY: Free Press.

Williamson, O. E. (1985). The economic institutional of capitalism. New York, NY: Free Press.

Wu, C. S. \& Shih, S. (2007). Selection of entry modes to a specific location using AHP group decision. Chiao Ta Management Review, 27(1), 199-223 (in Chinese).

Yiu, D. \& Makino, S. (2002). The choice between joint venture and wholly owned subsidiary: an institutional perspective. Organization Science, 13(6), 667-683. 
Zucker, L. (1983). Organizations as institutions. In Bacharach, S. B. (ed.), Research in the sociology of organizations (pp. 1-47). Greenwich, CN: Jai Press. 